\title{
OF MEN, HILLS AND WINDS: SPACE DIRECTIONALS IN MWOTLAP
}

\author{
Alexandre FRANÇOIS \\ LACITO-CNRS, Paris
}

\section{Summary}

In Mwotlap, an Oceanic language of Vanuatu, the principal device for referring to space is a paradigm of six directionals. Organized in pairs, these morphemes define three ways to draw a vector in space: by reference to a salient participant (hither-thither); by reference to an asymmetry perceptible within the immediate, local setting (up-down; in-out); or by reference to a fixed, absolute system of four horizontal quadrants (also lexified as up-down; in-out). These three "coordinate sets" can be shown to obey a strict hierarchy, determining which one the speaker should activate in a given situation. After providing an overview of this directional system, the current paper investigates in more detail the mechanics of geocentric reference in Mwotlap, whereby a land/sea axis (in-out) is crossed by a second axis, running from [south-] east (up) to [north-] west (down). In order to account for this use of the vertical directionals up-down on the horizontal plane, a semantic hypothesis is proposed, in relation with the seafaring history of Mwotlap's population.

to appear as:

François, Alexandre. 2003. Of men, hills and winds: Space directionals in Mwotlap. Oceanic Linguistics. 42 (2). Honolulu: University of Hawai'i Press. 


\section{OF MEN, HILLS AND WINDS:}

SPACE DIRECTIONALS IN MWOTLAP

\section{Introduction}

A foreign visitor living in the small island of Mwotlap, north of Vanuatu, could be impressed by the pervasiveness of space reference throughout this Pacific culture. ${ }^{1}$ As is often the case in Melanesia, the social identity of each individual, besides the reference to kinship, is deeply anchored in the island, the village, the area and even the house where they belong; and an important part of education on Mwotlap consists in being able to handle an incredibly tight network of placenames, as though every ten steps should bring us to a different site, with its own identity, history and legends.

Such an intense space-awareness in the culture of Mwotlap people has a corollary, as it were, in the language they speak: ${ }^{2}$ the sophistication of linguistic devices for the coding of space relations. These space-related words belong to different syntactic categories (François 2001): verbs, VP-internal adjuncts, directionals, adverbs, place names, prepositions, demonstratives, and even two aspect markers dedicated to spatial reference (François 2003:142-162). Although it is common for a language to possess verbs, adverbs or demonstratives with spatial semantics, the wealth of such devices throughout Mwotlap grammar is indeed worth underlining. All these words can be combined, following a strict order, which often results in clauses like $(1):^{3}$

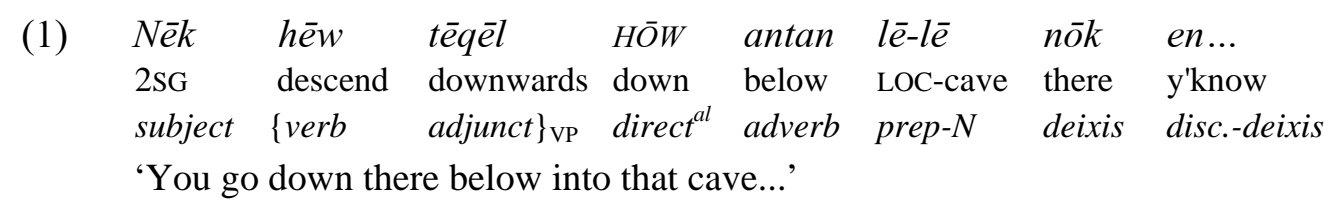

Much could be said about the syntax and semantics of all these spatial terms, how they interact with each other, what their possible and impossible combinations are. ${ }^{4}$ To begin with, we will choose to narrow down the scope of our study to an easily defined area of Mwotlap grammar: the small paradigm of directionals. 


\section{General properties of space directionals}

\subsection{Form and function of directionals}

These six spatial particles are so frequent in spontaneous speech, that they could be said to feature in almost every other sentence. They all are invariable monosyllables: hag 'up', howw 'down', hay 'in', yow 'out', me 'hither', van 'thither'. Although these directionals have also developed abstract, figurative meanings, ${ }^{5}$ the vast majority of their occurrences pertain directly to spatial reference.

Directionals occur after the verb, outside the verb phrase, just before locative complements; the order of constituents was given in example (1). In some cases, the directional can directly constitute the predicate, with a static meaning, as in (3a) or (5) below. If a sentence has only one spatial word, it will often be a directional; hence a possible paraphrase of (1) would be:

(1') Nēk van Hōw.
2SG go down
'You go down.'

Using a geometrical vocabulary, one could say that the function of directionals consists in "vectorizing" an event in space, i.e. orienting it along a certain axis. Unlike adverbs, directionals do not necessarily imply a specific goal: compare van $h \overline{o w}$ 'go down', which just encodes the direction of a movement, and van how antan 'go down below', aiming at a particular place (the ground, the bottom). This nuance explains why the category of directionals - referring to an axis-must be distinguished from that of locative adverbs-referring to a place.

The aim of the present paper is to provide a detailed description of how each vector is constructed in space, and what specific constraints underlie the selection of the proper directional, in relation with the physical and pragmatic context of utterance. The last section [\$4] will explore more specifically the mechanics of geocentric reference in Mwotlap.

\subsection{Directionals: motion path or deictic path?}

Each directional may refer to two distinct sorts of vectors: either the motion path actually followed by a moving item, or a mental path followed by the observer. This semantic ambiguity is evidently correlated with the question whether the relevant theme (subject or object) is in motion or not.

If a sentence mentions a theme that is spatially static, then the only function directionals can receive is to encode the mental pathway leading from the current situation of utterance towards that theme's location:

$$
\begin{array}{lllll}
K \bar{e} & \text { no-togtog } & H \bar{O} W & \text { Avay } & \text { (en). } \\
\text { 3SG } & \text { STA-dwell:DUP } & \text { down } & \text { A. } & \text { DX }
\end{array}
$$

'He lives down [there] in Avay village.'

In this case, the directional $h \bar{o} w$ 'down' does not reflect anybody's motion, since the subject is not moving. Rather, it represents a vector originating in the speaker's 
location (called $\mathrm{L}_{\mathrm{o}}$ ), and leading to the theme's position in space (called $\mathrm{X}$ ): this vector has thus the form $\left\{\mathrm{L}_{0} \rightarrow \mathrm{X}\right\}$.

This static reading of directionals is necessarily of a deictic nature, and will consequently vary based on $\mathrm{L}_{0}$, the location of the speaker. Let us illustrate this point with the example of three villages aligned from west to east on Mwotlap island: Lahlap, Avay and Aplow (see Figure 2 below); as we shall see later, the coordinates used in this case consider Lahlap to be 'down', Aplōw to be 'up', Avay lying in between. Now, let us imagine a telephone conversation between A in Aplōw and B in Lahlap, both speaking about a person C located in Avay. Although $\mathrm{A}$ and $\mathrm{B}$ are pointing to the same place, they must use different directionals:
(3a) Ave Wotlōlan, kē HōW Avay? - Oo, kē HAG Avay. where W. 3SG down A. yes 3SG up A.
A (from Aplōw): - Where is Wotlōlan? Is he down [there] in Avay?
B (from Lahlap): - Yes, he is up [there] in Avay.
[NO MOTION $\rightarrow$ directional reflects a deictic path]

The situation is different when the mentioned event involves a theme that is moving. In this case, the directional always represents the path of this motion, regardless of the deictic coordinates of the speech situation. Thus, the motion verb van 'walk, go' in (3b) entails that the directional be read as reflecting the intrinsic motion of the subject-a person walking from Lahlap 'up' to Avay (hence van hag 'go up, ascend'):

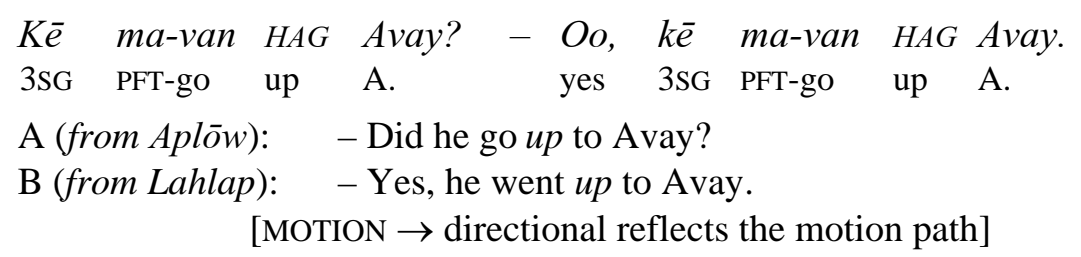

In examples like this, the reading of the directional is not deictic: both the origin and the target of the vector are internal to the reported event, and do not depend on the coordinates of the speech event.

Morphologically speaking, directionals are compatible both with the motionpath and the deictic-path readings, without any formal marking that would systematically clarify which one is being used-although, to be precise, the presence of a demonstrative, like en in (2), is often a good clue towards the deictic interpretation. As a rule, only the nature of the predicate, whether it is a motion event or a static location, makes it possible to calculate the right interpretation, and thus to construct the proper vector in space.

We will return to deixis in $\S 3.1 .3$.

\subsection{Mediate reference in vector construction}

When a static location is directly calculated by reference to the speech coordinates, the directional can appear on its own, as in (2) and (3a) above. But Mwotlap employs a different structure when the geometrical construction is mediate, i.e. when the vector's origin is a location $\mathrm{Z}$ different from the deictic 
center $\mathrm{L}_{\mathrm{o}}$. Thus, in addition to sentences such as "X is located up [from here]"with a vector of the form $\left\{\mathrm{L}_{0} \rightarrow \mathrm{X}\right\}$-it is also possible for the speaker to construct space relations via a landmark $\mathrm{Z}$, e.g. "X is located $u p$ in relation to the landmark $\mathrm{Z}^{\prime \prime}$; in the latter case, the vector must be formalized $\{\mathrm{Z} \rightarrow \mathrm{X}\}$.

The strategy here consists in first mentioning $\mathrm{Z}$ at the beginning of the sentence-unless it is already made clear in the context-and then use the directional representing the vector $\{\mathrm{Z} \rightarrow \mathrm{X}\}$, preceded by the morpheme lok, which normally means 'back, again':

$$
\begin{aligned}
& \text { Lahlap en, en tō... Avay, ba LOK Hōw. } \\
& \text { L. DX lie PCP A. but again down } \\
& \text { [uttered in Aplōw] 'Lahlap }(\mathrm{X}) \text { is located, er, (you know) Avay } \text { (Z) }_{(\mathrm{Z})} \\
& \text { well, downwards (from there/*from here).' }
\end{aligned}
$$

The mediate construction [lok + directional] is required whenever a static location is not introduced deictically, but makes reference to a distinct landmark Z. Since $\mathrm{Z}$ is necessarily known to the speech participants, we can consider this construction to follow a process of anaphora.

It can happen that the target $\mathrm{X}$ is located closer to the deictic center $\mathrm{L}_{\mathrm{o}}$ than the landmark $\mathrm{Z}$ : that is, the linear order of the three spots is $\mathrm{L}_{0}-\mathrm{X}-\mathrm{Z}$. If such is the case, the first directional must be followed by me 'hither', because the vector $\{\mathrm{Z} \rightarrow \mathrm{X}\}$ is then ultimately oriented towards the deictic center:

$$
\begin{aligned}
& \text { Avay en, en tō... Lahlap, ba LOK HAG ME. } \\
& \text { A. DX lie PCP L. but again up hither } \\
& \text { [uttered in Aplōw] 'Avay }(\mathrm{X}) \text { is located, er, (you know) Lahlap }(\mathrm{Z}) \text {, }
\end{aligned}
$$

Incidentally, this sequence $[(l o k)+$ directional $+m e]$ is the only context where two directionals can be combined; all other combinations are forbidden in Mwotlap. This restriction will have important effects on our investigation [\$3.4].

\section{Three coordinate sets for space reference}

The formal and functional properties we have reviewed so far are generally shared by all directionals. We can now examine the internal organization of this paradigm, and observe how these six morphemes encode distinct types of spatial relations. The analysis of the directional system will help us understand how Mwotlap speakers manage to handle different "coordinate sets" for space reference. After describing these strategies separately, we shall examine the hierarchy existing between them, in order to give a precise representation of the cognitive processes which are involved in the coding of space.

The six members of the paradigm appear to be organized in pairs, and ultimately define three distinct coordinate sets, in the geometrical sense. We will analyze successively:

- the coordinate set defined by reference to a participant

(one pair of directionals involved); 
- the coordinate set defined by reference to a local asymmetry (two pairs of directionals);

- $\quad$ the coordinate set defined by reference to geography (two pairs of directionals).

\subsection{Personal coordinates}

The first pair to be considered opposes me (glossed 'hither') to van (glossed 'thither'). Along with having grammaticalized as a directional, note that van is also synchronically the common verb for 'go'.

\subsubsection{ME 'hither, towards speaker'}

The form me indicates that the direction involved is towards the speaker, or a group of people to which the speaker belongs, or the portion of space where the speaker is located:

$$
\begin{array}{llll}
K \bar{e} & M E & \text { Vanuatu } & \text { agōh. } \\
\text { 3SG } & \text { hither } \quad \text { V. } & \text { DX:1 } \\
\text { 'He's here in Vanuatu.' (a place including the speaker's location) }
\end{array}
$$

Remarkably, Mwotlap lacks any verb lexeme equivalent to Eng. come. The encoding strategy here consists in combining me 'hither' with a motion verb (see Wilkins and Hill 1995:231 for Longgu):

$$
\begin{aligned}
& \text { Van ME! } \\
& \text { AO:go hither } \\
& \text { 'Come (towards me)!' }
\end{aligned}
$$

As is usually the case across languages, the point of reference for me 'hither' may be shifted to a deictic center distinct from the actual place of utterance. This is commonly the case in narratives, where deictic references often correlate to a character's point of view:

$$
\begin{array}{lllllllll}
\text { Tō } & \text { yañfala } & \text { en } & \text { ni-et } & \text { a } & \text { ni-siok } & \text { vitwag } & n i-h \bar{o} & \text { ME. } \\
\text { then } & \text { youngster } & \text { DX } & \text { AO-see } & \text { SUB } & \text { ART-canoe } & \text { one } & \text { AO-paddle } & \text { hither }
\end{array}
$$

'Suddenly the boy saw a canoe coming closer (to him/*to $m e$ ).'

The directional me appears not only with events of motion strictly speaking, but also commonly with events of transfer, speech, or any activity that would be directed towards (a group including) the speaker or deictic center:

$$
\begin{array}{llllll}
\text { (8a) Imam may vap } & \text { ME } & \text { hiy kamyō. } \\
\text { Dad } & \text { CPLT } & \text { say hither } & \text { DAT } & 1 \mathrm{EX} \text { DU }
\end{array}
$$

'Dad has already told us.' [lit. Dad has said hither to us.]

The mere presence of me makes it clear enough that the goal of the vector, i.e. often the recipient or beneficiary of an event, is - or includes-the speaker. This is why a sentence like (8a) will often leave implicit the prepositional phrase hiy kamyō 'to us', because the directional already suggests it: 
(8b) Imam may vap ME.

Dad CPLT say hither

'Dad has already told me/us.' [lit. Dad has said hither.]

Sometimes, the directional is the only indication that a beneficiary is implied in the event (François f/c $a$ ):

$\begin{array}{llll}\text { Lep! } & \text { vs. } & \text { Lep } & \text { ME! } \\ \text { AO:take } & & \text { AO:take hither } \\ \text { 'Take it!' } & \text { vs. } & \text { 'Give it to me/us! }\end{array}$

$\begin{array}{lllllll}\text { Ige } & \text { sil } & \text { mal } & \text { sigsig } & \text { sey } & \text { ME } & \text { ni-hnag. } \\ \text { PL } & \text { crowd } & \text { CPLT } & \text { contribute:DUP } & \text { gather } & \text { hither } & \text { ART-yam }\end{array}$

'People have already collected some yams for us.' [lit. collected hither]

\subsubsection{VAN 'thither, towards non-speaker'}

Among Oceanic languages, a word meaning 'towards speaker' (generally a reflex of POc *mai) is often contrasted with some other word glossed 'away from speaker' (often *atu, which has no reflex in Mwotlap); geometrically speaking, the latter gloss defines a bundle of possible vectors having the speaker or deictic center as their starting point, and any point in space as their target (Wilkins and Hill 1995: 236). But this definition 'away from speaker' does not seem to fit the semantics of Mwotlap van for two reasons: first, the origin of the van-vector is not necessarily the deictic center, and can be anything else; second, its goal must correspond to a specific element of the situation, whether an animate participant (other than the speaker) or an object. ${ }^{6}$

Rather than 'away from speaker', van should therefore be glossed 'towards non-speaker'. This nuance is illustrated by the two sentences below:

(11a) $N \bar{e}-b \bar{e} \quad e n$, nok luwyeg.

ART-water DX 1SG AO:pour.out

'Let me throw the water away.'

[away from speaker $\rightarrow$ zero]

(11b) Nē-bè en, nok luwyeg VAN.

ART-water DX 1SG AO:pour.out thither

'Let me throw the water on you/him/it.'

[towards non-speaker $\rightarrow$ van]

If no participant can be seen as the goal, then the directional must either be of a non-personal kind (e.g. hay 'in'), or simply be absent:
(12a) Hayveg VAN.
AO:enter thither

'Go in (towards him/her/them).' [suggests someone is inside]

(12b) Hayveg HaY. / Hayveg.

AO:enter in AO:enter

'Go in.' [suggests nobody is inside] 
The lexical distinction between '[go] towards addressee' and '[go] towards third person', attested elsewhere in Oceania (Ross f/c), is not made by Mwotlap van, which is ambiguous in this respect:

(13) Imam may vap VAN (hiy nēk/ kimil kēel kēy...). Dad CPLT say thither DAT 2SG 2PL 3SG 3PL

'Dad has already said it (to you/to him/to them.../*to me).'

Van always suggests a second or third person as the goal (e.g. beneficiary), in exactly the same way as me suggests a first person: compare (8) and (13). This is why these two directionals regularly respond to each other in dialogues like (14):

$\begin{array}{lllllll}\text { Lep } & \text { ME! } & - & \text { No } & \text { te-lep } & \text { qiyig } & V A N, \quad \text { ba makōh. } \\ \text { AO:take } & \text { hither } & 1 \mathrm{SG} & \text { FUT-take IMM thither but (wait) }\end{array}$

'Give it [to me]! - I'll give it [to you] in a minute, but wait.'

Crowley (2002:595) notes that "the particle /van/ can also be used to indicate that an action is performed for somebody else's benefit". This is because, to say it in our terms, this directional vectorizes the event towards a specific participant:

(15a) Nok so was ne-leleh nōnōm.

1SG PRSP wash ART-clothes your

'I will wash your clothes.'

(15b) Nok so was VAN ne-leleh nōnōm.

1SG PRSP wash thither ART-clothes your

'I will wash your clothes for you.'

To account for sentence (15b), an alternate interpretation would hypothesize a historical relation between this benefactive use of van and the POc verb *pani 'give' (Ross, pers. com.): the latter form could have grammaticalized in Mwotlap —as it has in other Oceanic languages (Lichtenberk 1985, Ross f/c) eventually merging with the reflex of *pano 'go'. But this hypothesis seems to be challenged by two arguments. First, diachronic rules of vowel umlaut (François 2001: 86 sqq.) strictly require that a regular reflex of *pani in modern Mwotlap be *ven, not van. Second, the use of van illustrated in (15b) is restricted to a beneficiary distinct from the speaker; if the latter is involved, then van must be replaced by me, as in ex.(9)-(10). This confirms that the morpheme van in (15b) is a reflex of POc *pano, and that an underlying spatial metaphor is involved in this kind of benefactive construction (François f/c $a$ ).

Finally, the target $\mathrm{X}$ of van need not be a person: it can be inanimate-whether the patient, or any element of the context that can be thought of as the event's goal. It is generally coded as a locative phrase, in a way consistent with the spatial metaphor underlying the semantics of van (lit. 'going thither towards $\mathrm{X}$ '); this is even the case when no actual motion is implied, like in (17):

$$
\begin{array}{llll}
K \bar{e} & n i-y e m & V A N & \text { lo-hos. } \\
3 \mathrm{SG} & \text { AO-climb } & \text { thither } & \text { LOC-horse }
\end{array}
$$

'So he climbed onto the horse.' $\quad[X=$ the horse $]$ 


$\begin{array}{lllll}\text { Na-wha } & \text { me-tnenen } & V A N & \text { l-eh } & \bar{e} g e \bar{n} . \\ \text { ART-music } & \text { PFT-straight } & \text { thither } & \text { LOC-song } & \text { now }\end{array}$

'The music is now perfectly adapted to the song.' $\quad[X=$ the song $]$

\subsubsection{Can we speak of deictic directionals?}

To sum up, the two directionals me and van both vectorize an event towards a specific participant, provided the latter is salient and relevant in the reference situation; the form me 'hither' is reserved for the case when the participant belongs to the sphere of the speaker (or of the deictic center), the form van 'thither' is used in all other cases. Both of these forms define a set of coordinates, which may be named "participant-oriented coordinates", or more simply "personal coordinates".

A brief note may be useful here, as to whether the two directionals me and van should be described as "deictic directionals". There are two ways in which a spatial vector can be assigned a deictic value, i.e. be construed according to the coordinates of the speech event. If we call $\mathrm{L}_{\mathrm{o}}$ the deictic center at the moment of utterance, we can define two sets of possible vectors:

- $\left\{\mathrm{x} \rightarrow \mathrm{L}_{\mathrm{o}}\right\}$

$\mathrm{L}_{\mathrm{o}}$ is the vector's target: this sort of deixis is coded by the personal directional me ('hither').

- $\quad\left\{\mathrm{L}_{0} \rightarrow \mathrm{x}\right\}$

$\mathrm{L}_{\mathrm{o}}$ is the vector's origin: we then have what we call the deictic reading of a directional [\$2.2]. The latter can be any of the six directionals, e.g. me in (5), $h a g$ and $h \bar{o} w$ in (3a); but none can be said to be inherently deictic, because having $L_{o}$ as their origin is just one possibility among others.

Strictly speaking, the only directional that is inherently deictic in Mwotlap is thus me 'hither', because it always entails reference to the deictic center $\mathrm{L}_{\mathrm{o}}$ (as the target). As for van, it is deictic only in two cases: when the motion has $\mathrm{L}_{0}$ as its origin ('thither from here') and/or when it has the addressee as its target ('thither to you'). But if the vector encoded by van has the form $\left\{\mathrm{x}_{1} \rightarrow \mathrm{x}_{2}\right\}$, as in sentence (16), then no reference is made to the coordinates of the speech event, and van cannot be described as being essentially "deictic".

\subsection{Local coordinates}

The four remaining directionals are defined by reference not to a participant, but to a physical feature of the local situation. This description corresponds to two types of local asymmetries: first, the vertical axis (up/down); second, what could be called the container perspective (in/out).

\subsubsection{The vertical asymmetry: up/down}

There should be no need to detail the contrast which exists between hag 'up' and $h \bar{o} w$ 'down', ${ }^{8}$ because it corresponds to a universal opposition along the vertical axis. What is relevant for our purpose here is to underline that this up/down contrast reflects a physical asymmetry which is perceptible whatever the scale of the observation: given any figure in the vertical plane, the mere effect of gravity 
always suffices to identify an upper and a lower part.

The following examples illustrate the uses of hag 'up' and hōw 'down' [see also (1) above]:

(18) Kèy me-yem kal qèt HAG le-vet liwo. 3PL PFT-climb upwards all up LOC-stone big

'They all climbed up the big rock.'

(19) $K \bar{e} \quad m \bar{e}-q \bar{e} s d i$ HōW tō ni-mat $H \bar{O} W$ agōh. 3SG PFT-fall down then AO-die down DX:1

'She fell down (from the tree) and died right down here.'

A comparison can be made with English up and down, except that the Mwotlap particles are probably more frequent. In fact, Mwotlap spatial directionals seem to be required whenever the event is vectorized in space, in one way or another. Hag will be found in all events where the notion of rising is involved, e.g. 'climb', 'wake', 'erect', 'grow', 'be day', 'begin':

$\begin{array}{llllllll}\begin{array}{l}E \\ E\end{array} t \bar{e}-y \bar{o} & e n & k \bar{e} & m i-l w o & H A G & e & k \bar{e} & \text { ma-malmal. } \\ \text { child-3DU } & \text { DX } & 3 \text { SG } & \text { PFT-big } & \text { up } & \text { DX } & 3 \text { SG } & \text { PFT-girl }\end{array}$

'Their child grew up and became a young woman.'

Likewise, $h \bar{o} w$ is required whenever the motion is downward: e.g. 'fall', 'sit', 'lie', 'bury', 'plant', 'be night', 'give birth', 'finish':

(21) Kēy galeg HōW n-ep. they AO:make down ART-fire

'They made a fire (on the ground).' [lit. They made down a fire.]

(22) Na-vap t-ā̄ag nan ni-bah HōW gēn. ART-word of-before ASSO AO:finish down DX:3

'And the tale ends [down] here.'

\subsubsection{The container asymmetry: in/out}

The second local dimension which is coded by Mwotlap directionals is the contrast between hay 'in' and yow 'out' . Contrary to the vertical axis, which is always given by experience, the in-out contrast presupposes a container of some sort, so that an inside can be opposed to an outside. This container is typically a house or a shelter, but it may be a box, a basket, a pocket:

(23) Kem so kal lō YOW aslil.

1EX:PL PRSP (move) outwards out outside

'We want to go out (of the house...).'

(24) Imam me-hn̄ēn bat nē-sēm HAY le-tbey nōnōm.

Dad PFT-stow inwards ART-money in LOC-basket your

'Dad has put the money in your bag.'

In a more figurative way, a containing figure can be seen, for example, in the shadow of a tree on the ground: 


$\begin{array}{llllll}\text { Dō } & \text { tig } & \text { bat } & \text { HAY } & \text { lo- } \bar{m} o l \bar{m} o l & \text { en. } \\ \text { 1IN:DU } & \text { AO:stand } & \text { inwards } & \text { in } & \text { LOC-shade } & \text { DX }\end{array}$

'Let's go and stand in the shade.'

Conversely, the directional yow 'out' is often associated with large, open-air places like the dancing area in the village, or a clearing in the forest—as in (33) below.

\subsubsection{Two sets of locally-based coordinates}

If the speaker has to vectorize an event along the vertical axis, he will be able to use the directionals $h a g / h \overline{o w}$. If the direction coincides with a "container perspective"-whether horizontal or vertical-, it will also be possible for him to encode it as going 'in' (hay) or 'out' (yow).

In case both criteria are met at once, then the dimension perceptually more salient must be chosen. Thus, in (24), if the bag is prominently perceived as a closed figure - e.g. having the shape of a purse, with a narrow opening - then the event will certainly be encoded as putting the money 'in' (hay); but if instead it is a rather flat basket lying on the floor, then the 'entering' motion may become less salient than the vertical dimension, in such a way that the same event would more probably be described as putting the money 'down' (how). This kind of ambiguous situation, in which the speaker has to select one strategy over the other, are very common in discourse: we shall meet similar cases again later in the present study [\$3.4].

To sum up, what is common between the two pairs of directionals up/down and in/out is that they define a set of spatial coordinates through the identification of a physical asymmetry in the local setting. The only case they do not cover is when a vector extends on the horizontal plane-so that the up/down constrast becomes irrelevant — and it cannot easily be associated with any containing figure-which makes the in/out pair useless too. This is precisely where, as we shall see now, geographically-based coordinates come into their own.

\subsection{Geocentric coordinates}

The two mechanisms we have been reviewing so far based spatial reference on the local features of the proximate situation, either with relation to a participant involved (melvan), or with relation to what we have called a local asymmetry (hag/hōw, hay/yow). The third strategy we shall examine expresses space relations in terms of absolute coordinates: vectors are defined by reference to a set of four directions, which conventionally divide the horizontal plane into four equal quadrants.

\subsubsection{Two axes: one fixed, one variable}

To some extent, the four directions of the geocentric system can be compared with the four absolute, cardinal directions (east, west, north, south) of European languages. But one important difference is that only one of Mwotlap's two axes is spatially fixed, independent from the observer's location; in a way, it is the only one that really deserves to be called a 'cardinal axis'. Its orientation could be 
described, at least temporarily, as roughly extending from 'east' (hag) to 'west' $(h \bar{o} w)$-but note that a more precise description will be the concern of $\S 4.2$.

As is common among Austronesian languages (Senft ed. 1997), the second axis opposes a 'landward' (hay) to a 'seaward' (yow) direction; its actual reference, in terms of cardinal points, changes according to the side of the island under consideration. Because the mountain range runs roughly from east to west, yow 'seawards' will point to the north on the northern part of the island of Mwotlap, but to the south on its southern part (Figure 1). ${ }^{10}$ As for the east-west "cardinal" axis, it will correspond to a direction parallel to the shore.

Figure 1 - The two axes of the Mwotlap geocentric system

(a) geographic coordinates on northern side of the watershed

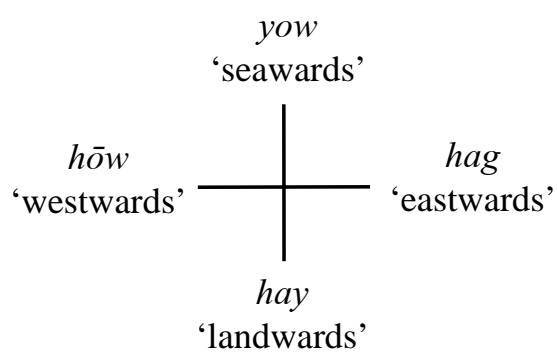

(b) geographic coordinates on southern side of the watershed

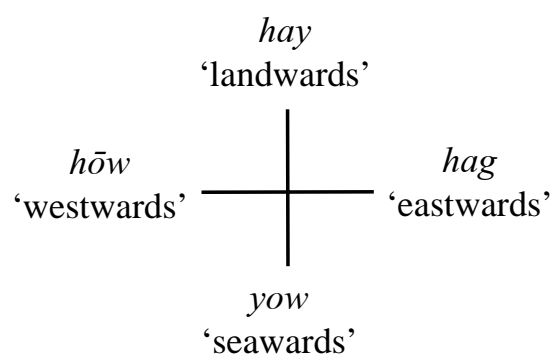

In this framework, going 'landwards' ( hay) corresponds to a motion perpendicular to the shore and directed towards what can be described as the "watershed" of the island. Since the inhabited area is rather low and flat, this "watershed" is sometimes nothing else than an invisible, abstract boundary extending west to east through the middle of the island, and cutting across the villages. Young speakers just learn conventionally where the line is supposed to be drawn, as this is precisely the place where they get used to reversing the coordinate system, from (a) to (b) in Figure 1.

Figure 2 gives a more realistic idea of how geocentric coordinates define directions on Mwotlap; it shows that the axis we first described as east-west is in fact slightly rotated ENE-WSW. The watershed is represented, as well as the seven villages of the island.

Figure 2 - Geocentric coordinates in Mwotlap: one fixed cardinal axis (hag-hōw), one axis depending on the watershed (hay-yow)

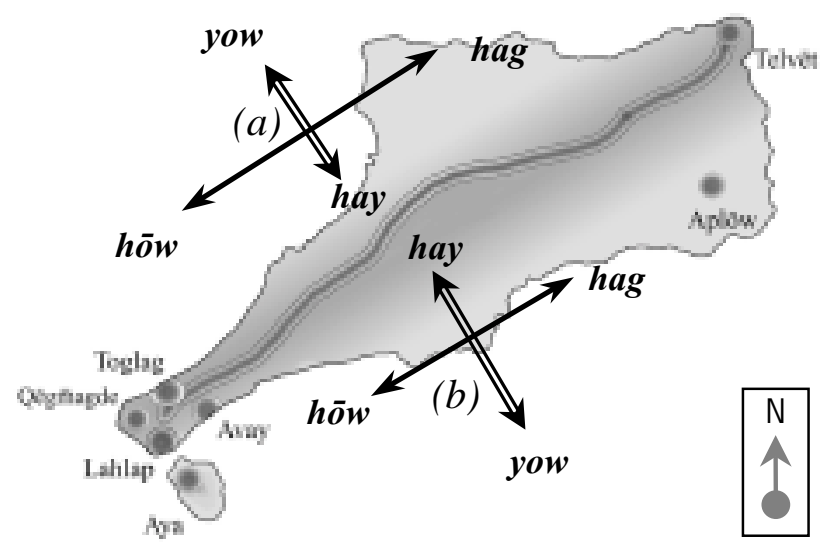


Although the direction hay is ultimately bounded (Palmer 2002:122) by the watershed, it can freely be used at sea to indicate the direction of a specific island in the vicinity, e.g. '(paddle...) towards the island/the shore' [see $§ 4.1, \S 4.2 .3$ ]; Symmetrically, the opposite direction yow extends far out from the island, and points to the 'open sea' in the context of seafaring.

\subsubsection{Homophony between directionals?}

The reader will already have noticed the homophony between the four members of the geocentric system (e.g. hag 'eastwards'), and what we called earlier the four local directionals (e.g. hag 'up'); this issue will be addressed in detail in $\$ 4$. But from the speakers' point of view, elucidating this homophony (e.g. 'eastwards' = 'up'?) is not a necessary prerequisite before the geocentric system can be used properly. Every Mwotlap speaker grows up in a social environment which is already entirely "vectorized" along these abstract axes (Levinson 1996b: 371); and as long as one remains in the well-known setting of the village or the island, one just needs to reproduce these arbitrary conventions to locate things in space. The mechanism of geocentric orientation only demands thorough mastery when one reaches novel, unfamiliar landscapes [\$4.2.2].

Suffice it to say, the homophony here mentioned is largely felt to be arbitrary by the speakers themselves, who can barely account for this formal coincidence. This is why we prefer to describe these four directionals as being fundamentally twofold: for example, hag both means 'up' along the vertical axis (local coordinates), and 'eastwards' on the horizontal plane (geocentric coordinates), with no obvious possibility to merge these two distinct meanings into one [see $\S 4.2 .5]$.

\subsubsection{Geocentric coordinates and physical distances}

Even though the motivation of the coordinates themselves may belong to the large scale of a whole landscape (the mountain, the sea, the east and west...), their actual use commonly fits in any scale, from the largest-several miles-to the smallest-less than an inch. The first case, i.e. large-scale use of geocentric coordinates, will not be surprising to the Westerner, because this is also the norm in English:

(4a) Lahlap en, en tō... Avay, ba LOK HōW. L. DX lie PCP A. but again west

'Lahlap is located to the west of Avay.'

But sentences like the following, on a smaller scale, are also extremely common in Mwotlap:

(26) En malig HAG!

AO:lie shift east

'Please shift yourself eastwards.'

(27) Suwyeg nē-be $\bar{e}$ HAY anen.

AO:throw.away ART-water inland DX:2

'Just throw the water there [close to you (anen), inland side].' 
The spatial use of the anthropomorphical coordinates left and right is utterly unknown in Mwotlap; and both what Levinson (1996 $a, b)$ names "intrinsic" and "relative" frames of reference (e.g. in front of $\mathrm{x} /$ behind $\mathrm{x}$ ) are seldom used, if ever. Basically, when a vector on the horizontal plane needs to be encoded-whatever the scale - the use of the absolute frame will be the default strategy. In this regard, the system of Mwotlap space reference, like that of several other languages of Oceania (e.g. Hyslop 2002 for North-East Ambae, Vanuatu), is similar to the one described for Guugu Yimithirr (Levinson 1992, Haviland 1993, Foley 1997:217). We will come back to Mwotlap geocentric reference in $\S 4$.

\subsection{The Coordinate-set Hierarchy Hypothesis}

We have shown how the system of Mwotlap directionals exploits three different cognitive strategies; each one consists in selecting certain features of the environment, and making them the source of a coordinate set for the coding of spatial relations:

(a) the personal strategy bases the coordinates on the identification of a relevant participant, animate or not, as the target of the vector ('hither/thither');

(b) the local strategy bases the coordinates on certain asymmetries which are physically perceptible within a limited situation ('up/down', 'in/out');

(c) the geocentric strategy makes reference to two perpendicular axes ('east/west', 'inland/seaward') which are conventionally mapped onto the landscape, dividing the horizontal plane into four balanced, symmetrical quadrants.

Now, as we briefly mentioned in $\$ 2.3$ above, a crucial fact about Mwotlap directionals is that they hardly ever combine with each other: phrases like *hag hay 'up + inland' or *van yow 'thither + out' are ungrammatical, and only one directional can be chosen at a time-with the exception of the construction in (4b). As a consequence, vectorizing an event in space implies the selection of the strategy most relevant to the situation, either $(a),(b)$ or $(c)$.

As far as large-scale reference is concerned, for instance when referring to distances between villages or islands, the geocentric strategy is the norm, for obvious reasons. But whenever a vector has to be constructed on a smaller scale, e.g. within one's field of vision, then each of the three strategies mentioned here is theoretically possible, and indeed well attested. Our problem is now the following: when more than one encoding strategy is possible, on what basis do Mwotlap speakers select the proper one? For example, if a motion is both coming towards the addressee and going east, which directional will be chosen by the speaker: van 'thither' or hag 'eastwards'?

Far from being random, this choice obeys certain rules that deserve a detailed examination. Based on a few tests and examples, we would like to develop here what we call the Coordinate-set Hierarchy Hypothesis-i.e. the idea that there exists a constant, regular hierarchy between the three strategies we have defined for Mwotlap.

\subsubsection{Personal strategy $>$ Geocentric strategy}

The first case to be examined is the relation between $(a)$ 'personal strategy' and (c) 'geocentric strategy'. When a given event is both oriented towards a 
participant $\mathrm{X}$ and along a horizontal axis which could be represented in geocentric terms, it appears that the personal directionals will always take priority over the geocentric ones.

This can be seen, for example, in the following context. Speaker A and speaker B were both sitting at a table, facing each other. On each side of the square table was a teacup, as represented in Figure 3; the geocentric coordinates of the test setting are also indicated.

Figure 3 - Personal vs. geocentric directionals:

one table, two speakers, four cups

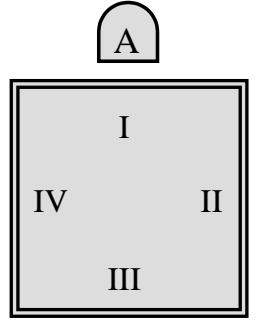

B

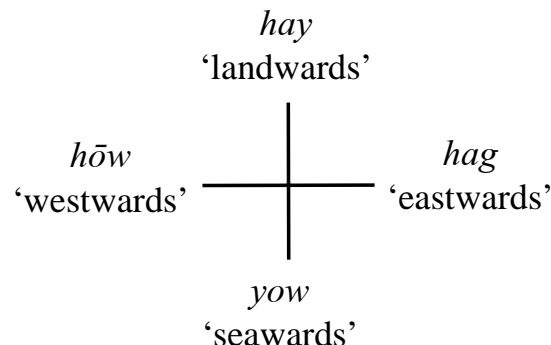

$\mathrm{B}$ asked $\mathrm{A}$ to designate verbally each teacup on the table. The two cups placed on the sides of the table where nobody was sitting (i.e. II and IV) would be designated through geocentric coordinates:

(28a) na-ban̄kēn mey hag tō lok HAG ART-cup REL sit PCP again east

'the cup which is eastward (II)'

On the contrary, cups $I$ and $I I I$ would never be designated by reference to geography, but to the person they were obviously associated with, and physically close to. In this case, the personal directionals were used, usually combining with a demonstrative:

(28b) na-bañkēn mey hag tō lok VAN anen ART-cup REL sit PCP again thither DX:2

'the cup which is towards you (III)'

Here, the use of the geocentric strategy (...lok yow 'the cup seaward') would have been considered awkward or rude, as it would ignore the participants in presence, despite their high saliency in the situation.

This observation, which was made in this case on a very small scale, can also be made in larger contexts, as long as the participants are perceived as present in the situation. For example, on the large football field of Lahlap village, let us imagine a player A telling his fellow $\mathrm{B}$ to send the ball to a third player $\mathrm{C}$, who happens to be standing on the western side of the field. In this case, because the participant $\mathrm{C}$ is both salient and pragmatically relevant, the personal strategy would be the norm: 
(29a) Nēk so kik VAN hiy Pēlēt!
2SG PRSP kick thither to Fred
'You should kick (the ball) to Fred!'

The use of the geocentric system would only be appropriate if A were asking B to send the ball not to someone in particular, but to a specific portion of space, irrespective of the presence of other participants there:

(29b) Nēk so kik lok HōW!

2SG PRSP kick again west

'You should kick (the ball) westwards!'

To sum up, whenever a direction can be represented by reference both to a participant and to a cardinal direction, the personal strategy (me 'hither'/ van 'thither') will take priority over the geocentric one. ${ }^{11}$ We can infer from this a hierarchy of the form $(a)>(c)$.

\subsubsection{Personal strategy $>$ Local strategy}

A similar reasoning holds for the relation between $(a)$ 'personal strategy' and $(b)$ 'local strategy'. When both these coordinate sets are relevant, it appears once again that the personal set (a) will always take priority.

Among other examples, this hierarchy was evidenced in a spontaneous situation we faced in the field, once again at tea-time. In the preceding days, we had already heard people utter sentences like (30a), while pouring tea in a cup placed on the table:

(30a) Ni-ti en, nok sey HōW la-ban̄kēn nōnōm. ART-tea DX 1SG AO:pour down LOC-cup your

lit. 'Let me pour some tea down in your cup.'

But the situation was utterly different when the drinker held his cup in his hands: his saliency in the context would then make him a natural reference point in order to establish the spatial vector associated with sey 'pour'. In this case, (30a) would have sounded rude, and the only appropriate phrasing would make use of the personal strategy:

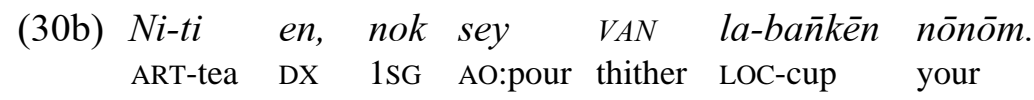

lit. 'Let me pour some tea thither in your cup.'

It is therefore legitimate to posit a second hierarchy between two spatial strategies, of the form $(a)>(b)$. Note that the same observation was already suggested by an example such as (12a-b).

Privileging the personal coordinate set over the local one does not necessarily prevent the latter from featuring in the sentence: the direction in local terms can be encoded on the verb, or another morpheme of the clause, like the verbmodifying adjunct [see (1)]: 
(31) Lep bat ME na-tā̄ anen.

AO:take inwards hither ART-bag DX:2

'Bring that bag in (towards me).'

Thus, in cases where English says come up ('personal' + 'local'), Mwotlap uses the reverse encoding strategy, literally saying ascend hither [compare with (6)]:

$$
\begin{array}{ll}
V \bar{e} y k a l & M E ! \\
\text { AO:ascend } & \text { hither }
\end{array}
$$

'Come up!'

\subsubsection{Local strategy > Geocentric strategy}

Likewise, if a movement in space corresponds both to a local asymmetry and to a geocentric axis, the former will always have the priority over the latter; in other words, there is a strong hierarchy of the form $(b)>(c)$.

\section{- Container perspective vs. geocentric system}

Let's consider the "container perspective" (in-out). If somebody is walking in a certain direction, without any local asymmetry perceptible, then the geocentric coordinates will be the default: the subject will be said to go eastwards (hag), or westwards $(h \bar{o} w)$, or seawards (yow), etc. But as soon as the motion can be related to a containing figure in the close situation (e.g. a house, a covered area), then this geocentric system will be overruled by the local system (in-out), regardless of the direction which is followed in cardinal terms.

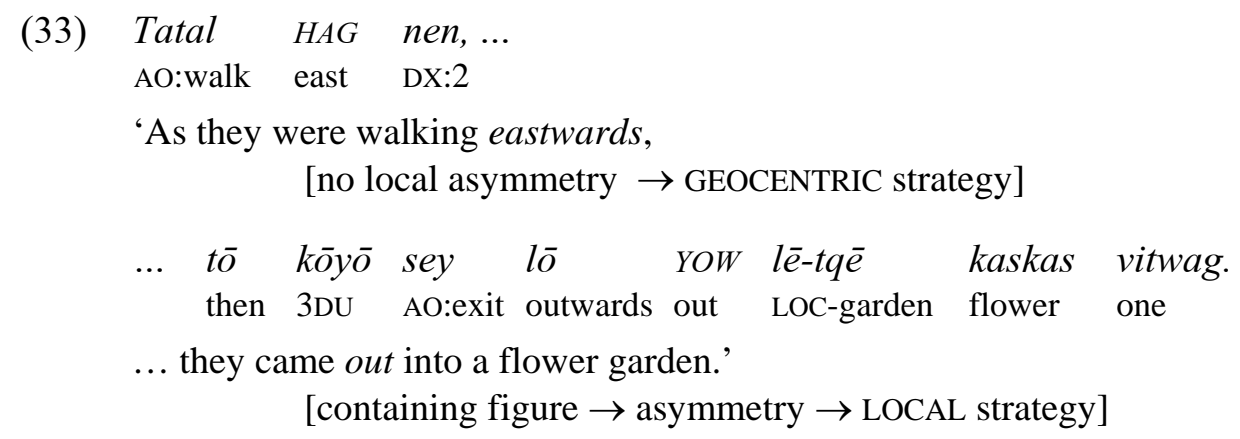

\section{- Vertical axis vs. geocentric system}

The same applies for the vertical axis (up-down). Suppose someone is walking from the shore landwards, towards the heights of the island: this motion could potentially be represented either using the local asymmetry system, i.e. the vertical axis, or the geocentric system, i.e. the land/sea axis. Indeed, both systems are possible here, according to the perception one has of the motion.

If the slope is particularly steep, then the physical feeling of going upwards will be perceptually salient over the geocentric one, and the local system will be preferred (van hag 'go up'). Conversely, if the slope is gentle, as is the case in most parts of the island, then the motion will be conceived as essentially horizontal; the geocentric coordinates will then provide the only strategy available for linguistic encoding (van hay 'go inland'). ${ }^{12}$ 
In a way reminiscent of (31)-(32) above, the selection of a geocentric directional does not preclude the use of the vertical axis elsewhere in the sentence. It is therefore common to hear combinations of two distinct reference strategies in the same clause, following the pattern: local coordinates on the verb and/or the adjunct, geocentric coordinates on the directional:

$\begin{array}{llllll}\text { Nō-lōmgep } & s u & n i-h \bar{e} w & \text { tèqēl } & \text { YOW } & \text { ale. } \\ \text { ART-boy } & \text { small } & \text { AO-descend } & \text { downwards } & \text { seawards } & \text { on.shore }\end{array}$

'The little boy walked down to the beach.' [lit. descended seawards]

\section{- Each situation imposes its own geometry}

Finally, it is important to note that the hierarchy Local > Geocentric has nothing to do either with the nature of the objects located, or with their canonical position in space. On a small scale, both coordinate sets are equally common; the choice of the proper one will depend on which is more relevant for the encoding of a given vector, based on the specific geometry of the current situation.

This strict situational dependence became obvious one day, as someone was looking at a photo album where each page had two pictures, one above the other. As long as the album was held more or less vertically, the only relevant strategy employed to designate either photo was the vertical axis, regardless of the geographic setting:

$$
\begin{aligned}
& \text { (35a) no-totgal mey lok HAG alge } \\
& \text { ART-picture REL again up above } \\
& \text { 'the picture up above' }
\end{aligned}
$$

But as soon as the album was put horizontally, on somebody's lap or on a table, then reference to a local asymmetry (specifically the vertical axis) became impossible. That was when the geocentric system had to be activated:

(35b) no-totgal mey lok YOW

ART-picture REL again seawards

'the picture seaward'

Crucially, one will notice that, when the album is horizontal, European languages would continue to refer to the pictures as being respectively 'above' and 'below', virtually referring to the canonical position of the book in the reader's hands, and/or to the typical way of reading (see Levinson 1996b:373). On the contrary, spatial coordinates in Mwotlap are calculated with reference to the current position of the object in the specific event situation, without any mental projection into its usual or intended use: this is made clear in (35b).

As far as our discussion is concerned, this means that the priority rule Local > Geocentric only holds if a local asymmetry (in/out or up/down) can actually be perceived in the geometry of the current situation.

\subsubsection{Synthesis: the Coordinate-set Hierarchy Hypothesis}

We have successively demonstrated three binary hierarchies: first $(a)>(c)$, then $(a)>(b)$, and finally $(b)>(c)$. It is not difficult to infer from these a ternary 
relation, of the form $(a)>(b)>(c)$. This corresponds to what we have termed the Coordinate-set Hierarchy Hypothesis:

$$
\text { Personal strategy }>\text { Local strategy }>\text { Geocentric strategy }
$$

According to this hypothesis, when Mwotlap speakers need to vectorize an event in space, they mentally scan through three sets of coordinates, following a strict order of priorities, until they identify the most appropriate directional. These mental operations are synthesized in Figure 4.

Figure 4 - The architecture of space: how to select the proper directional in Mwotlap

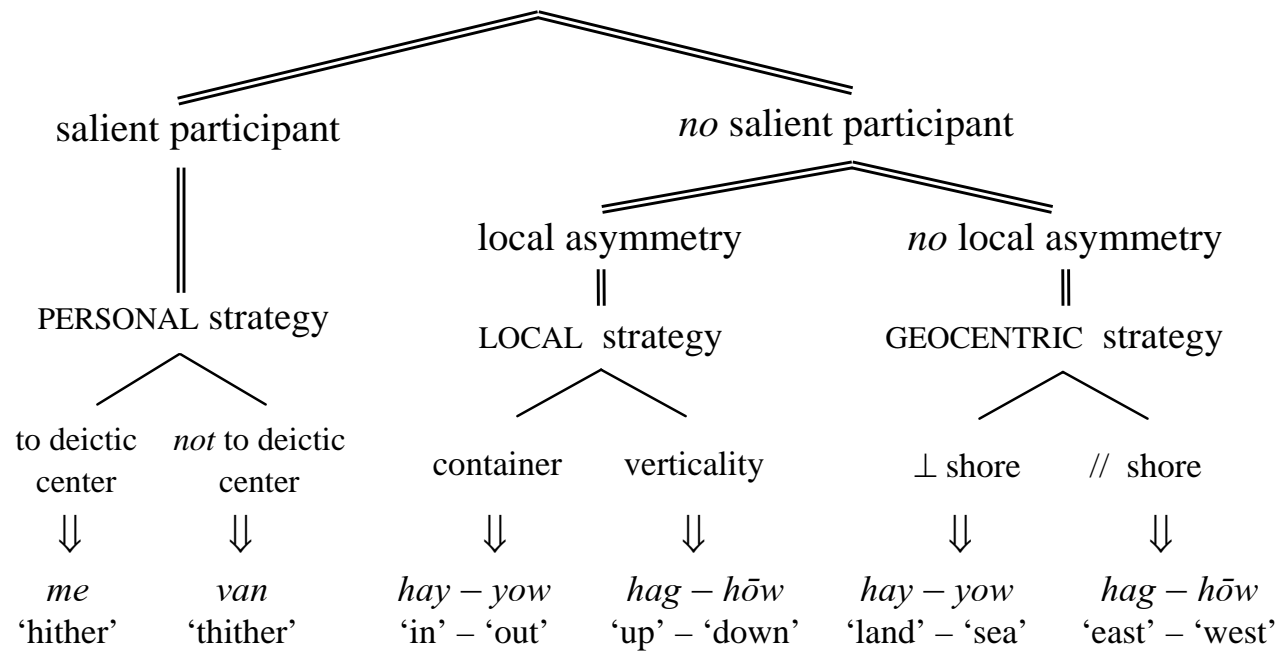

These observations show that the geocentric system is only used as a default, i.e. when other strategies are not available. This point is instructive in two respects. On the one hand, being the default space-encoding strategy explains why geocentric directionals are so pervasive in Mwotlap speech. But on the other hand, it suggests that the importance of geocentric reference, which attracts the foreigner's attention because of its exoticism, should somehow be relativized: considered from within the mechanics of the system, it is no more than one encoding strategy among others, and it even seems to correspond to the device with the lowest weight and saliency.

The first part of this paper has detailed the three coordinate sets used in Mwotlap space reference, and the hierarchical relationship which holds between them. Yet, although the information we have given on directionals was sufficient for this initial overview of the space system, a more detailed description is now required in order to fully understand the ins and outs of Mwotlap's geographicallybased reference system.

\section{The geocentric system: A double metaphor}

Until now, all that has been said of the four geocentric directionals concerned their synchronic use in a specific system of spatial coordinates, distinct from other 
strategies available to the speaker; in this framework, the only relevant explanation consisted in describing how the system divides horizontal space into four equal, symmetrical quadrants (\$3.3). Now, a second step in the observation should try and account for the way these four directions are lexified, and see how this particular system may have arisen. Indeed, we still have to explain the exact formal parallelism between what we have called the local and the geocentric directionals:

Table 1 - Local and geocentric readings of four space directionals

\begin{tabular}{|c|c|c|}
\hline directional & local reading & geocentric reading \\
\hline hay & in & landwards \\
yow & out & seawards \\
hag & up & east (?) \\
hōw & down & west (?) \\
\hline
\end{tabular}

Our concern will now be to understand the semantic motivations of such a parallelism. Incidentally, this new approach will trigger a small change in our word-to-word principles: whereas the preceding section carefully distinguished between the local and the geocentric translations for a single morpheme (e.g. hag glossed 'up' vs. 'east'), from now on the directionals will systematically receive their gloss in local terms (e.g. hag always glossed 'up'), whatever their actual reading.

\subsection{The island as a container}

The first case we will examine draws a relation between the local directions 'in'/'out' and the geocentric ones 'landwards'/'seawards'. The reason for this formal similarity is not difficult to figure out: the island is perceived as a container, the outside of which corresponds to the surrounding sea. Walking from one spot on the island towards the beach is equivalent to going 'outwards' (yow), and conversely any motion towards the interior of the island (notice the same metaphor in English), even on a very short distance, is thought of as 'inward' (hay). The metaphor suggested by the directionals hay/yow is commonly reinforced by other words of the sentence, like the verb or the adjunct:

$\begin{array}{llllll}\text { (36a) } & \text { Ni-siok } & \text { so } & \text { ni-hayveg } & \text { bat } & \text { HAY le-pnō. } \\ \text { ART-canoe } & \text { PRSP } & \text { AO-enter } & \text { inwards } & \text { in } & \text { LOC-island }\end{array}$

'The canoe was heading towards the island.'

[lit. entering inwards in the island]

But despite its intuitive appeal, this metaphor "inland = in" is not to be taken for granted. First, it should be noted that apart from Mwotlap-plus a couple of neighboring languages - there aren't many Oceanic languages which have the same image; most of them either use specific words for 'inland' vs. 'sea', or employ the vertical axis ('up'-'down') for this purpose [see note 12]. And in fact, the latter possibility is not unknown in Mwotlap: even if it is not done with directionals, resorting to the vertical axis to encode the land/sea contrast is at least commonly done on the verb or the adjunct-compare with (34) on land. This is 
the case even when no vertical motion is involved: observe how the next sentence, still representing a canoe at sea, suggests two simultaneous equations ("inland = up" and "inland = in"):

$\begin{array}{lllll}\text { (36b) Ni-siok } & \text { so } & n i-v e \bar{e} k a l & \text { HAY alge. } \\ \text { ART-canoe } & \text { PRSP } & \text { AO-ascend } & \text { in above }\end{array}$

'The canoe was heading towards the island.' [lit. ascending in above]

Moreover, other metaphors appear to even contradict the equation "inland = in". The technical register of seafaring, despite using directionals normally (hay 'towards the island' $\neq$ yow 'towards the open sea'), also employs locative adverbs exactly in the opposite way: alon [lit. 'inside'] is 'in the open sea', whereas aslil [lit. 'outside', see (23)] means 'on the shore'. (36c) illustrates this stunning contradiction between two distinct images, hay suggesting the equation "inland = in", whereas aslil points to the opposite metaphor "ocean = in":

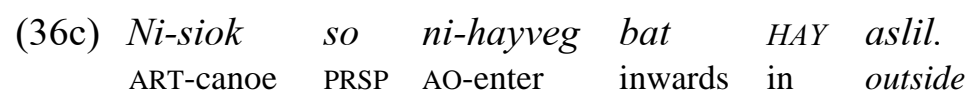

'The canoe was heading ashore.' [lit. entering in outside]

Yet, even if the surrounding verbs or adverbs can indeed show different strategies, the two directionals hay and yow are constant in identifying the island as a containing figure.

Consequently, the land/sea axis, although belonging to the geocentric coordinate set, can ultimately be explained as a mere extension of the local system on the scale of a whole island. In order to characterize a horizontal motion perpendicular to the shore (e.g. walking across the village clearing, or pushing a cup on the table), we can imagine a speaker of Mwotlap searching first for a local asymmetry (Figure 4); if none were to be found in the close environment, this speaker would "stand back", so to speak, and ultimately look for an asymmetry on a wider scale. This is how a small move on the horizontal plane, which at first glance looks impossible to describe in local terms (i.e. being neither inward nor outward, neither upward nor downward), can nonetheless be assigned to some asymmetry, provided the whole shape of the island is taken into account.

Nonetheless, although this description ultimately merges the local and the geocentric systems ("inland $=$ in"), it is not necessarily the case that the comparison is consciously activated every time the land/sea axis is used. It is probably more realistic to conceive this semantic extension as a historical event, a linguistic innovation that happened at some date in the past. ${ }^{13}$ For the modern speaker, this metaphor is not necessarily obvious, and at least seems to be acquired by children much later than the geocentric system itself.

\subsection{The up-down axis on the horizontal plane}

The mechanics of the up-down axis are even more opaque to the majority of speakers. Very few people on Mwotlap are able to explain why East is 'up' (hag), and West is 'down' $(h \bar{o} w)$; nothing justifies this parallelism in the geography of the island, as if it were higher in its eastern part. ${ }^{14}$ Other motivations remain to be explored, such as one which would derive this up-down contrast from the path of 
the sun, or from the direction of prevailing winds; our demonstration will eventually prove the latter to be the right explanation.

Incidentally, note that we shall regularly refer to this up-down axis as "the cardinal axis" of the system. As we have explained in \$3.3.1, such a terminological choice is justified by the relative fixedness of its orientation in cardinal terms, regardless of one's position on an island-which is not the case, obviously, for the land/sea contrast. Nevertheless, this section will also give us an opportunity to refine the description of this "cardinal" axis, and realize it is more complex than a simple 'east'-'west' direction.

\subsubsection{The path-of-the-sun hypothesis}

A probable explanation, which is sometimes proposed by native speakers themselves, would make a relation with the path of the sun. Following a conceivablethough unclear-metaphor, the place where the sun rises would be understood as being 'up', whereas the sunset would be coded as 'down'. This hypothesis could be confirmed by the usual association of hag 'up' with the morning or sunrise, and $h \bar{o} w$ 'down' with the evening or sunset [but see note 5]:

$$
\begin{array}{llll}
T \bar{o} & \text { mahe } & \text { ni-mtap } & H A G \text {. } \\
\text { then place } & \text { AO-morning } & \text { up }
\end{array}
$$

'Then dawn began to rise.' [lit. It was morning up.]

(38) Tō mahē ni-qō̄ $H \bar{O} W$.

then place AO-night down

'Then night fell.' [ [it. It was night down.]

Moreover, certain Oceanic languages, whose system is similar to that of Mwotlap, are described along these lines. Longgu (Hill 1997), a language spoken on Guadalcanal, has a cardinal axis running from WNW to ESE, i.e. roughly from 'west' (toli, originally 'down') to 'east' (ala'a, originally 'up'). Following the suggestion of her informants, the author proposes that this axis is "derived from the rising and the setting of the sun" (Hill 1997:106)—see the discussion in François ( $\mathrm{f} / \mathrm{c} b)$.

Indeed, this was initially the interpretation we had personally formed to account for the cardinal axis of Mwotlap. But later on, several elements made us challenge our own hypothesis. First of all, we were not fully satisfied with the idea that speakers of a language could spontaneously say I am going up when what was meant would be 'I am going towards the place where the sun rises'. A second thought was that if the path of the sun were so salient to Mwotlap speakers, then it should have been used constantly in all landscapes, both on Mwotlap and on other islands. But travelling around Vanuatu with Mwotlavians helped us realize this was not the case.

\subsubsection{Mwotlap outside Mwotlap}

In Port-Vila, the capital of Vanuatu where many Mwotlap speakers live, the rising of the sun does not take place in the hag direction, but hay 'inland': 


$$
\begin{array}{llllllll}
\text { Vila, } & \text { na-lo } & \text { ni-hatig } & \text { lok } & H A Y, & \text { lok } & H A G & \text { te. } \\
\text { V. } & \text { ART-sun } & \text { AO-get.up } & \text { again } & \text { in/inland } & \text { again } & \text { up/east? } & \text { NEG }
\end{array}
$$

'In Vila, the sun rises towards the inland side (hay), not the hag-side.'

Indeed, in the context of Vila (Figure 5), the geocentric axes correspond to totally different directions from those used on the island of Mwotlap. The land/sea axis (hay-yow), which by definition is orthogonal to the shore, is physically oriented from east to west; and the up-down axis, which is necessarily perpendicular to the latter, runs from due north ( $h \overline{o w}$ 'down') to due south (hag 'up').

Figure 5 - Mwotlap geocentric directionals in the capital Port-Vila

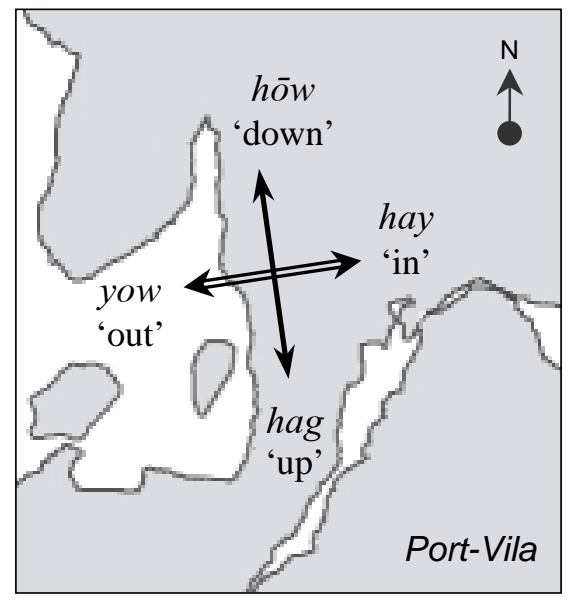

In comparison with the system we have seen at work so far on the island of Mwotlap, the reason for rotating the whole system this way is obviously that the main shore in Vila is oriented north to south. Before going any further in the investigation, these first observations already provide evidence towards some interesting conclusions. When speakers of Mwotlap find themselves in a new landscape, the axis which they establish first is the land/sea axis (coded in-out), probably because the shore, and the declivity of the ground, are perceptually the most salient features of the landscape (Palmer 2002: 131). Once the latter axis has been established, a second axis is drawn, orthogonal to it, and thus necessarily parallel to the shore. This logical hierarchy is evidenced by the fact that the land/sea axis always determines the direction of the second axis, never the other way around. ${ }^{15}$

Now, if Mwotlap behaved here like several Oceanic languages which leave this "traverse axis" unspecified (Palmer 2002; François f/c $b$ ), there would be no need for further discussion, since the second axis would simply be defined by the orientation of the shore. But the system of Mwotlap additionally requires the speaker to orient it along a "conceptual slope" (Levinson 1996b: 371) oriented up-down. In this case, how do speakers calculate the orientation of this cross axis, and assign, say, the up-direction ( $h a g$ ) to the proper side of the landscape?

To be precise, the speakers themselves do not bother with this question, as long as they remain on the island where they were born and raised; it only becomes relevant in the particular situation when one reaches unfamiliar landscapes, and has to adapt to the change of environment. This is why the best way to understand 
the Mwotlap system involves observing how Mwotlap speakers, leaving the shores of their own island, manage to find their bearings in other landscapes.

The example of Vila (Figure 5), which we had noticed by chance, gave us the idea of extending the inquiry to other islands of Vanuatu. When we could not visit an island ourself, we looked for people who were familiar with it. Of course, the test didn't involve asking people to use maps themselves, which would have proven difficult for them and led to dubious results; instead, for each area covered, several individuals were asked whether going from a place $X$ to a place Y (e.g. two familiar villages) would mean going hag 'up' or $h \bar{o} w$ 'down'. The results were generally consistent, and when they were not, a brief discussion would help select the correct answer. Incidentally, the habit of using geocentric directionals even when referring to imaginary or remote settings is a mental activity Mwotlap people are familiar with, especially through the tradition of story-telling. Each time a reliable answer was achieved, we could draw arrows on our maps, and thus research empirically the nature of the geocentric up-down axis in Mwotlap. The results of this investigation are presented in Figure 6, where each arrow points to the direction called hag 'up'.

Figure 6 - How Mwotlap geocentric directional hag 'up' is employed on other islands of Vanuatu

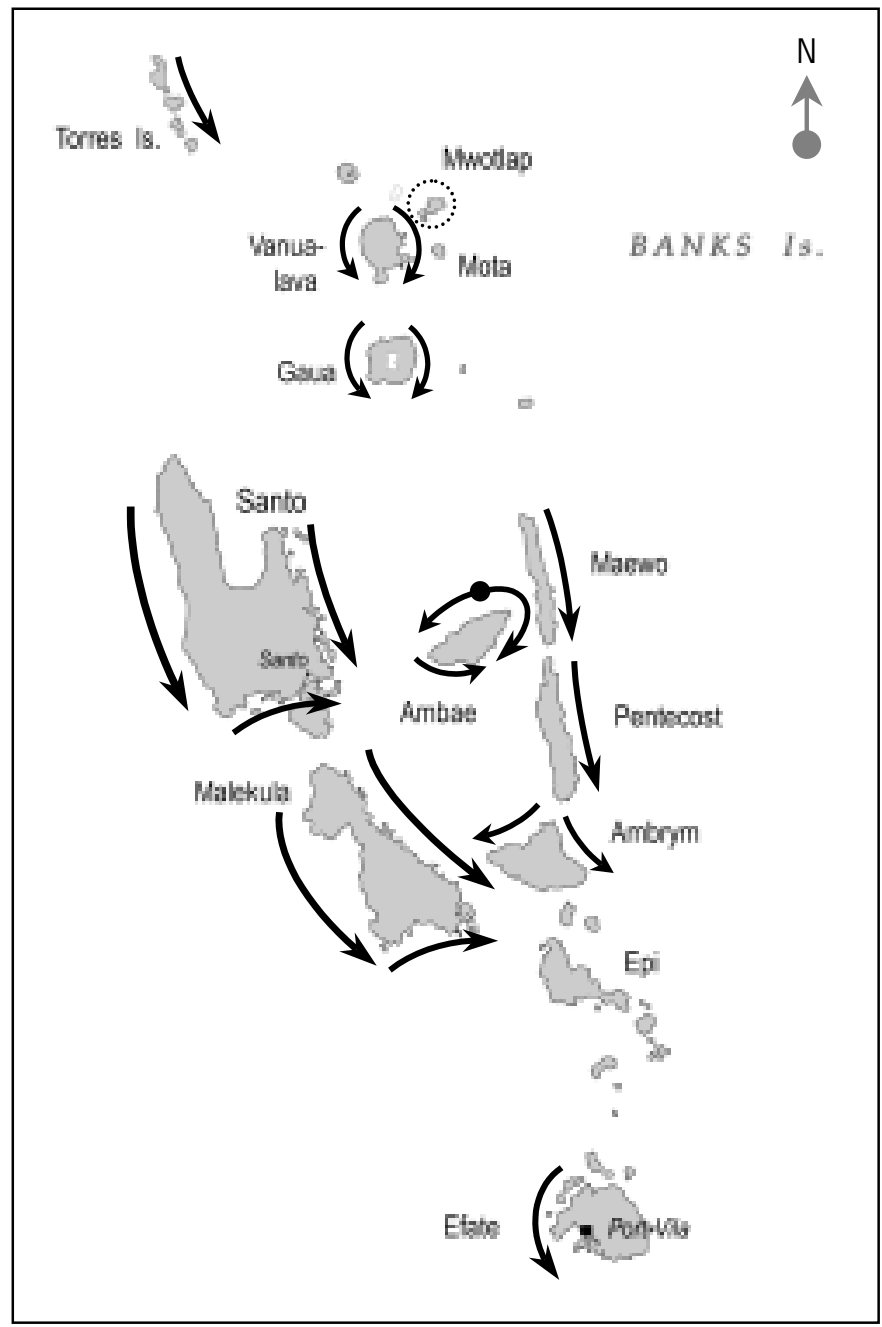


As Figure 6 shows, the directional hag 'up' is far from pointing constantly towards the rising of the sun. According to the orientation of the shore, the down $\rightarrow$ up axis may correspond to several different directions:

- $\quad\{\mathrm{W} \rightarrow \mathrm{E}\}$, as on both sides of Mwotlap, on southern Ambae, southern Santo, southern Malekula;

- $\quad\{\mathrm{N} \rightarrow \mathrm{S}\}$, as on both sides of Vanua-lava, Gaua, Santo, Maewo, Pentecost, Efate (and also in the town of Port-Vila: Figure 5);

- $\quad\{\mathrm{NW} \rightarrow \mathrm{SE}\}$, as in the Torres, on both sides of Malekula, on eastern Ambrym;

- $\quad\{\mathrm{NE} \rightarrow \mathrm{SW}\}$, as on the western side of Ambrym, on the eastern and western sides of Ambae.

Despite the apparent inconsistency between all these directions, it remains possible to conflate them into a single, "mean" vector, which would run from northwest to southeast. And indeed, it appears that the direction hag is never directed north, nor due west. Rather, all the attested vectors fit within the limits of a single (virtual) semi-circle, which is the southeastern half of space. Any geocentric direction belonging to this conceptual half will be encoded as hag 'up' in Mwotlap, and conversely, any motion directed towards north and/or west will be encoded as how 'down'. The geometry of the Mwotlap cardinal axis is represented in Figure 7.

Figure 7 - The cardinal (up-down) axis in Mwotlap: all attested $u p$-directions belong to the southeastern half of space

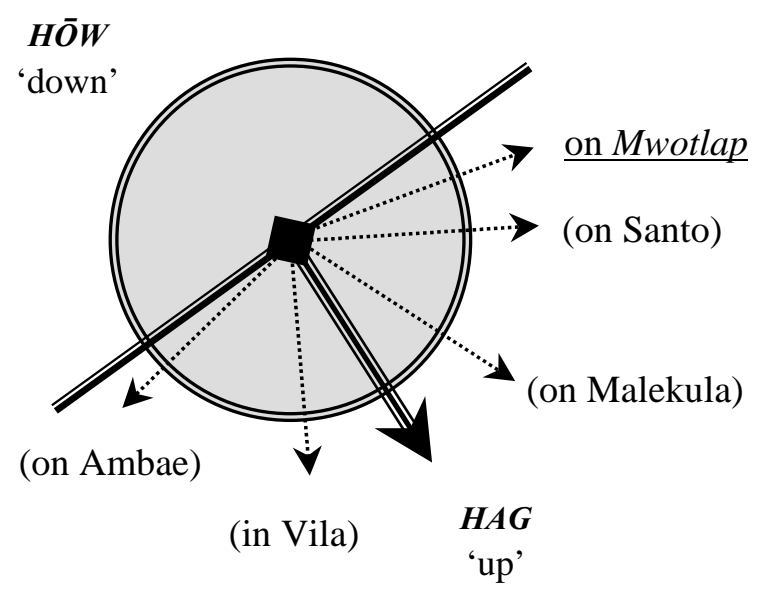

The main arrow, representing due southeast, could be named the 'prototypical value' of the geocentric directional hag: it is the idealized average of all the empirically attested hag-directions. But the latter can designate directions which are in fact remote from this prototype, even if the difference is never greater than $90^{\circ}$. Remarkably, this is true about the island of Mwotlap itself. Far from providing hag with its prototypical value, the cardinal axis there is rotated to the extreme limits of the semi-circle-up to $80^{\circ}$ anticlockwise-so as to fit with the shape of the landscape. This is why the first description we gave here of the geocentric directionals $h a g-h \bar{w} w$ as meaning respectively 'east' and 'west' was in fact only true in the context of Mwotlap, and false elsewhere. Despite being apparently inaccurate, our choice was justified by the fact that the majority of 
speakers who remain in their island have no need for assigning any other meaning to these two directionals.

But there is an even more instructive conclusion to draw here. Knowing that the language of Mwotlap has been spoken almost exclusively on the island of the same name for several centuries, one would have expected the speakers of Mwotlap, after many generations of learning to identify 'up' with '[north-]east', to finally reanalyze this as the typical meaning of hag, before adapting it to new places. On the contrary, the use of the geocentric system in their native island has continued until today to correspond to a marginal reading of the NW-SE cardinal axis (Figure 7); the latter system, which arguably was historically prior to its modern Mwotlap version, has thus been preserved across generations. To account for such a paradoxical conservation, there must have been a specific speech context in which Mwotlap speakers would regularly bring back the cardinal system to their attention and memory. This context was the art of seafaring.

\subsubsection{Geocentric reference on the navigational scale}

\section{- Directionals at sea}

The last section examined how the cardinal up-down axis was regularly projected onto the terrestrial shape of other islands; but nothing was said of its use at sea. Although the last generations of Mwotlap have abandoned the art of sailing, they are still used to paddling along the coast with small individual canoes, and also to visiting the neighboring islands with modern motor boats-to say nothing of Chinese cargo vessels. These journeys on the sea are still the occasion to employ the geocentric system of reference, but in a context which may be called "navigational scale" (Palmer 2002: 131).

The reader will remember $[\$ 3.3 .1]$ that the land/sea axis extends far out to sea. When a boat is coming closer to a given island, it will be said to go hay 'in' [ex. (36a-c)]; conversely, paddling away from it will be expressed with yow 'out'. This use of hay and yow at sea is orthogonal to the shore under consideration, following exactly the same pattern as on dry land. Likewise, as long as the island is in sight, the cardinal up-down axis will be parallel to that same shore, and will vary according to its shape. For example, people paddling close to the coast of Mwotlap will continue to mean 'westwards (along the coast)' when using the directional $h \bar{o} w$, as they would do on land.

But things become different when no island can be seen, or when the presence of an island is pragmatically irrelevant. In this case, the land-sea axis (hay-yow) naturally disappears, and the only axis to be activated is the up-down one (hag$h \bar{o} w$ ), dividing the whole maritime space into two halves instead of four quarters. And because no shoreline imposes its tortuous shape, the direction of the up direction becomes crystal-clear: it points due southeast, strongly confirming the hypothesis of Figure 7.

\section{- From one island to another}

The same rules apply when somebody, located on one island, wants to refer to another island. Indeed, although it is grammatically possible to refer to a place 
only by its name:
(40)
Nok so hohole Santo.
1SG PRSP speak:DUP S.
'I want to phone (somebody in) Santo.'

the presence of a directional will be almost systematic:

$\begin{array}{llllll}(40 ') & \text { Nok } & \text { so } & \text { hohole } & \text { HAG } & \text { Santo. } \\ 1 \text { SG } & \text { PRSP } & \text { speak:DUP up } & \text { S. }\end{array}$

[uttered on Mwotlap I.] 'I want to phone (somebody in) Santo up there.'

Now, the choice of the proper directional, which we found difficult to make when we were in the field, is in fact straightforward. Hag 'up' is associated with all islands located southeast of Mwotlap: Mota, Gaua, Santo, Ambae, Maewo, Efate (and the capital Port-Vila), Tanna...; it is also used for all foreign countries (New Caledonia, Australia, France, USA), probably because one has to go first to the capital before flying abroad. Conversely, the directional $h \overline{o w}$ 'down' is associated with islands northwest of Mwotlap: Ureparapara, the Torres Is.; and the Solomons, despite being a foreign country, are also designated as $h \bar{o} w$, because long-standing trade relations between the Banks and the Santa Cruz archipelagoes have led people to know the exact location of this country. ${ }^{16}$ Of course, when the situation is reversed, the directional just needs to be reversed: i.e. if Vila is $u p$ from Mwotlap, conversely Mwotlap is down from Vila, and so on.

Taking Mwotlap island as the origin, Figure 8 shows how the navigational scale of this language divides the whole world, so to speak, in two halves.

Figure 8 - The world is divided in two halves, one up and one down; a third directional is used in the special case of Vanua-lava

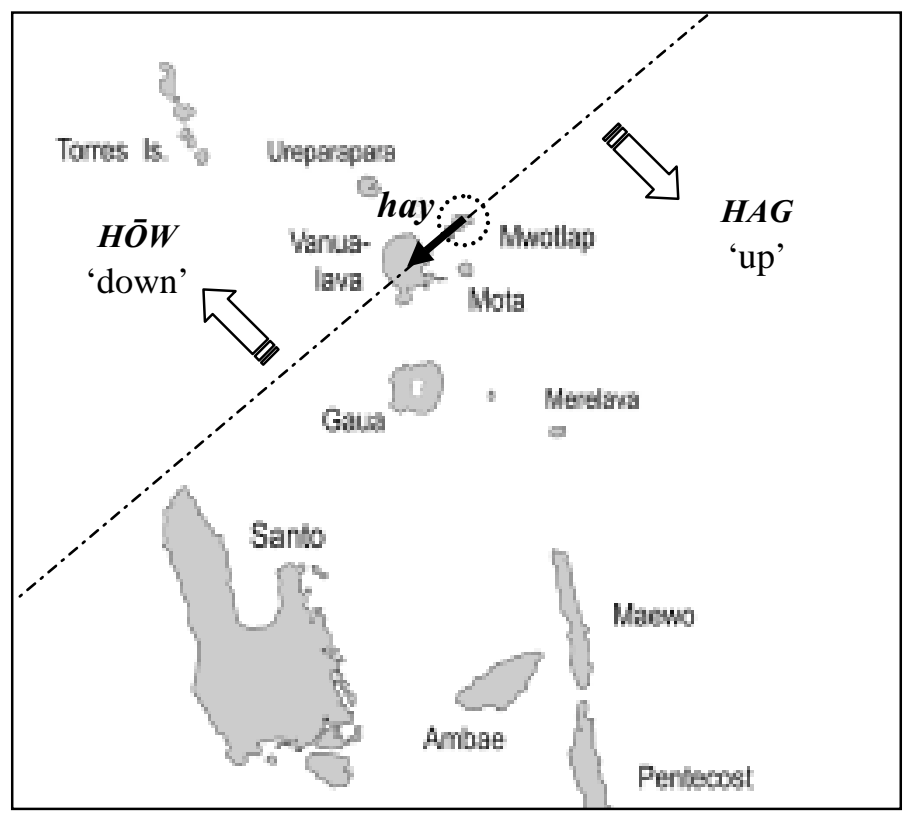




\section{- The special case of visible islands}

As Figure 8 suggests, the language of Mwotlap only seems to have met a difficulty when trying to assign a proper directional to the island of Vanua-lava. Indeed, this huge island is located exactly southwest of Mwotlap, making it impossible to refer to it either as being up (hag) or down $(h \overline{o w}) .{ }^{17}$ Exceptionally, the directional used in this case is hay 'inland'; and symmetrically, someone located on Vanua-lava will designate Mwotlap as being yow 'seawards'.

The reason for having chosen hay certainly has to do with the high volcano of Vanua-lava, which dominates the horizon when seen from Mwotlap. Indeed, the land/sea axis is sometimes used between two islands A and B, provided they are visible from each other. If $A$ is lower than $B$, then people from $A$ will refer to $B$ as being hay 'inland', as if they were in the position of a ship approaching land; conversely, people from B will have the feeling of pointing yow 'out to sea' when considering a lower island. Remarkably, this rule does not depend on the relative size of A and B, but only on their relative height: thus the inhabitants of Mwotlap, who predominantly live in low coastal villages, designate as hay both the high and huge island of Vanua-lava to their southwest, and the high and small islet of Aya to their immediate southeast (Figure 2). But apart from this exceptional case of a few islands that are visible from each other, all other cases make regular use of the global cardinal (up-down) axis.

\subsubsection{Sailing into the wind}

One question still remains to be answered. What does this southeast direction stand for? And why is it lexified as ' $u p$ '?

Southeast has definitely nothing to do with the sun, nor does it correspond to any salient astral phenomenon. However, it does reflect a natural element, wellknown to all the sailors of the South Pacific: the wind-more precisely the trade winds, which in that part of the world blow from southeast towards the equator. Because, at least until recently, the people of Mwotlap used to sail, the direction of the prevailing winds continued to play an important role in their system of spatial reference: sailors at sea don't have many clues other than the wind, when trying to orient themselves; some form of seafaring astronomy is sometimes reported for these Oceanic populations (Osmond 2000), but it has been lost for several generations in Mwotlap. Incidentally, the names of the four principal Mwotlap winds are: Yēqo 'SE wind', Wōvet 'NE wind', Togle 'NW wind', Kēyēbē 'SW wind'.

As for the use of the two local directionals hag 'up' and how 'down', it probably results from a metaphor, the same which motivates the pair of English directionals upwind vs. downwind. A boat heading into the wind meets the same kind of physical resistance as a man walking up a steep slope, and conversely, to sail with the wind astern appears to be as easy and swift as for somebody to run down a hill (Françoise Ozanne-Rivierre, pers. com.). If this interpretation is true, then the use of this wind-based axis on dry land is obviously secondary, and results from the mapping on land of a referential system which was elaborated essentially at sea, by a seafaring culture (see François f/c $b$ ). 
The trade-wind hypothesis has been proposed by several scholars to account for similar facts in the languages of the Pacific: among others, Lavondès (1983) for Marquesan; Ozanne-Rivierre (1997:85) for several languages of Polynesia and of New Caledonia; Hyslop (2001:216) for North-East Ambae. But even if their explanations did of course help us eventually solve the last step of our reasoning, our principle has been not to take any explanation for granted, before trying to disentangle our field data; this conclusion was thus arrived at independently, following an essentially empirical methodology.

We could only find a couple of elderly people in Mwotlap, who clearly confirmed that the up-down contrast was originally in relation to the wind. Though, even if the metaphor involved in the up-down axis is opaque to contemporary speakers, it is still common to reinforce the directional by a verb and/or an adjunct and/or an adverb of the same basic (vertical) meaning:

$$
\begin{array}{lllll}
\text { Dōyō } & \text { so } & \text { veykal HAG alge. } \\
\text { 1IN:DU } & \text { PRSP } & \text { ascend up above }
\end{array}
$$

'We should go (south-)eastwards.' [lit. we should ascend up above]

$$
\begin{array}{llllll}
N \bar{e} k & t \bar{e}-h \bar{e} w & t \bar{e} q \bar{e} l & H \bar{O} W & \bar{M} \text { otlap } & \bar{n} \bar{e} h ? \\
\text { 2SG } & \text { FUT-descend } & \text { downwards } & \text { down } & \text { M. } & \text { when }
\end{array}
$$

[uttered in Santo] 'When will you go down to Mwotlap?'

The apparent up-down movement in such sentences is purely metaphorical, and does not correspond to anything on the vertical axis.

\subsubsection{Summary}

The last pages demonstrated that the geocentric axis coded $h \bar{o} w$-hag, despite running from (south-) west to (north-) east on the island of Mwotlap, corresponds in fact to a global axis oriented from northwest to southeast; its overall direction, as well as its lexical expression as up-down, are historically motivated by the path of the trade winds. This axis can be activated in two different ways. When the speaker is at sea, or refers to long-distance relations between islands, then the cardinal axis regularly points southeast, dividing space into two equal halves, one 'down' and one 'up' (Figure 8). But when the speaker is on dry land, or on a boat close to an island, then the cardinal axis combines with the land/sea axis, defining four equal quarters. If the system has to be applied to a novel landscape, then the land/sea axis is always assigned in priority, whereas the up/down axis is secondarily mapped onto the contours of the island; this adaptive process may involve pivoting the cardinal up away from the actual southeast, though never more than $90^{\circ}$ on each side.

Once again, this semantic parallelism illustrates how the local coordinate setin this case the vertical axis-has been extended so as to encode a set of coordinates belonging to the horizontal plane. But if the use of in-out for the land/sea axis could be seen simply as the widening in space of the "container perspective" [§4.1], the example of up-down is somewhat different, because it involves an obscure metaphor that is no longer accessible to the average speaker of Mwotlap. Consequently, even after elucidating the double metaphor at the 
source of the four geocentric directionals, it is still necessary to distinguish structurally between what we have called the local and the geocentric coordinate sets-although they make use of exactly the same morphemes.

Table 2 summarizes the mechanism of geocentric reference in Mwotlap.

Table 2 - The four geocentric directionals of Mwotlap: summary

\begin{tabular}{|c|c|c|}
\hline & HAY - YOW & HAG - HŌW \\
\hline Local coordinate set & $\begin{array}{l}\text { container perspective } \\
\text { 'in' - 'out' }\end{array}$ & $\begin{array}{l}\text { vertical axis } \\
\text { 'up' - 'down' }\end{array}$ \\
\hline $\begin{array}{l}\text { Geocentric } \\
\text { coordinate set }\end{array}$ & 'inland' - 'out to sea' & 'upwind' - 'downwind' \\
\hline $\begin{array}{l}\text { underlying } \\
\text { metaphor }\end{array}$ & $\begin{aligned} & i \text { sland } \\
&= \text { container } \\
&\end{aligned}$ & $\begin{aligned} & \text { facing the wind } \\
&= \text { climbing up a slope } \\
&\end{aligned}$ \\
\hline $\begin{array}{l}\text { ON LAND } \\
\text { (whatever the scale) } \\
\text { or } \\
\text { AT SEA } \\
\text { close to/with reference } \\
\text { to an island }\end{array}$ & $\begin{array}{c}\text { define two quadrants } \\
\text { orthogonal to shoreline: } \\
\text { in = towards (middle of) island } \\
\text { out }=\text { towards (deep) sea }\end{array}$ & $\begin{array}{c}\text { define two quadrants } \\
\text { parallel to shoreline: } \\
u p \approx \text { towards SE } \\
\text { down } \approx \text { towards NW } \\
\text { [precise orientation may be up to } \\
90^{\circ} \text { away from cardinal SE/NW, } \\
\text { depending on the shoreline] }\end{array}$ \\
\hline $\begin{array}{l}\text { AT SEA } \\
\text { with no island } \\
\text { in sight or in mind }\end{array}$ & - & $\begin{array}{c}\text { divide space in two halves: } \\
\text { up }=\text { towards SE } \\
\text { down }=\text { towards NW }\end{array}$ \\
\hline
\end{tabular}

\section{Conclusion}

The linguistic act of referring to space consists in looking for asymmetries, even when, at first sight, none are perceptible. In Mwotlap, the use of personal and deictic coordinates is far from being unknown, and can even be said to receive priority over other coordinates. But often the speaker finds it impossible, or pragmatically irrelevant, to encode a direction by referring to the event participants, or to a local situation; in this case, the default strategy resorts to a set of four horizontal quadrants, whose arrangement is recalculated in each new setting. Ultimately, this four-term system can be shown to be motivated by the structure of the environment, of which certain features appear to be-or to have been in the past—culturally significant, and hence cognitively salient. The asymmetry of the land/sea contrast is a daily reality for these populations, who dwell mainly on coasts, and whose diet combines root crops and seafood. And the art of navigation, so deeply entrenched in the history of Oceanic cultures, has made it possible to organize space along another asymmetry, namely the path of the strongest winds.

The next step in this research would entail comparing the Mwotlap system with that of other Oceanic languages which have been described to date, with the aim to formulate hypotheses on the historical development of these geocentric directionals-see François $(\mathrm{f} / \mathrm{c} b)$. And of course, the more languages are described in the future, the better we will understand these intricate issues. 


\section{References}

Adelaar, Sander. 1997. An exploration of directional systems in west Indonesia and Madagascar. In G. Senft (ed.), pp.53-81.

Bennardo, Giovanni (ed.). 2002. Representing space in Oceania: Culture in language and mind. Pacific Linguistics, 523. Canberra: Australian National University.

Blust, Robert. 1997. Semantic change and the conceptualization of spatial relationships in Austronesian languages. In G. Senft (ed.), pp.39-51.

Bowden, John. 1992. Behind the preposition: Grammaticalisation of locatives in Oceanic languages. Pacific Linguistics, B-107. Canberra: Australian National University.

Bugenhagen, Robert. 1995. A grammar of Mangap-Mbula: An Austronesian language of Papua New Guinea. Pacific Linguistics, C-101. Canberra: Australian National University.

Codrington, Reverend. 1885. The Melanesian languages. Oxford: Clarendon Press.

__ and Palmer, Jim. 1896. A dictionary of the language of Mota, Sugarloaf Island, Banks Islands. London: Society for Promoting Christian Knowledge.

Crowley, Terry. 2002. Mwotlap. In J. Lynch, M. Ross and T. Crowley (eds), The Oceanic languages. London: Curzon Press. Pp.587-598.

Foley, William. 1997. Anthropological linguistics: An introduction. Language in Society. Oxford: Blackwell.

François, Alexandre. 2001. Contraintes de structures et liberté dans la construction du discours: Une description du mwotlap, langue océanienne du Vanuatu. Doctoral dissertation (unpublished). Paris: Université Paris-IV Sorbonne. 1078 pp.

_- 2003. La sémantique du prédicat en mwotlap (Vanuatu). Collection Linguistique, Société de Linguistique de Paris, vol. LXXXIV. Paris, Louvain: Peeters. xx + 388 pp.

- - forthcoming $a$. Desperately seeking benefactives in Mwotlap. In A. Margetts (ed.), Coding for benefactives in Oceanic languages [provisional title, publisher unknown].

-_. forthcoming $b$. Reconstructing the geocentric system of Proto Oceanic. Oceanic Linguistics. University of Hawai'i Press.

_- in progress. Dictionnaire encyclopédique mwotlap. Computer files. Paris: LACITO.

Haviland, John. 1993. Anchoring, iconicity and orientation in Guugu Yimithirr pointing gestures. Journal of Linguistic Anthropology 3 (1), 3-45.

Hill, Deborah. 1997. Finding your way in Longgu: Geographical reference in a Solomon Islands language. In G. Senft (ed.), pp.101-126.

Hyslop, Catriona. 2001. The Lolovoli dialect of the North-East Ambae language, Vanuatu. Pacific Linguistics, 515. Canberra: Australian National University.

- - 2002. Hiding behind trees on Ambae: Spatial reference in an Oceanic language of Vanuatu. In G. Bennardo (ed.), pp.47-76.

Keesing, Roger. 1997. Constructing space in Kwaio (Solomon Islands). In G. Senft (ed.), pp.127-141.

Lavondès, Henri. 1983. Le vocabulaire marquisien de l'orientation dans l'espace. L'Ethnographie 79 (1): 35-42.

de León, Lourdes. 1994. Explorations in the acquisition of geocentric location by Tzotzil children. Linguistics 32, 857-884.

Levinson, Stephen. 1992. Language and cognition: the cognitive consequences of spatial description in Guugu Yimithirr. Working paper no. 13: Cognitive Anthropology Research Group, Max Planck Institute for Psycholinguistics.

- - $1996 a$. Frames of reference and Molyneux's question: Crosslinguistic evidence. In P. Bloom, M. Peterson, L. Nadel and M. Garrett (eds.), Language and space, pp.109-170. Cambridge, MA: The MIT Press.

-_. 1996 b. Language and space. Annual Review of Anthropology, 25: 353-382.

Lichtenberk, Frantisek. 1985. Syntactic-Category Change in Oceanic Languages. Oceanic Linguistics 24: 1-84. 
Osmond, Meredith. 2000. Star, wind and wave: searching for early Oceanic navigation terms. In B. Palmer and P. Geraghty (eds), SICOL: Proceedings of the Second International Conference on Oceanic Linguistics, vol.2: Historical and descriptive studies. Pacific Linguistics. Canberra: Australian National University. Pp.3-35.

Ozanne-Rivierre, Françoise. 1997. Spatial reference in New Caledonian languages. In G. Senft (ed.), pp. 84-100.

- - . forthcoming. Spatial deixis in Iaai (Loyalty Islands). In G. Senft (ed.), Deixis and demonstratives in Oceanic Languages. Pacific Linguistics. Canberra: Australian National University.

Palmer, Bill. 2002. Absolute spatial reference and the grammaticalisation of perceptually salient phenomena. In G. Bennardo (ed.), pp. 107-157.

Ross, Malcolm. forthcoming. The grammaticisation of directional verbs in Oceanic languages. In I. Bril and F. Ozanne-Rivierre (eds), Complex predicates in Oceanic languages: Studies in the dynamics of boundedness and compacity. [publisher unknown].

Senft, Gunter. 1997. Introduction. In G. Senft (ed.), pp.1-38.

-_ (ed.). 1997. Referring to space. Studies in Austronesian and Papuan languages. Oxford Studies in Anthropological Linguistics. Oxford: Oxford University Press.

Streicher, J. F. 1982. Jabêm-English dictionary. Pacific Linguistics, C-68. Canberra: Australian National University.

Tryon, Darrell. 1976. New Hebrides Languages: An internal classification. Pacific Linguistics, C-50. Canberra: Australian National University.

Wilkins, David and Hill, Deborah. 1995. When go means come. Cognitive Linguistics 6, 209-259.

\section{Notes}

${ }^{1}$ This paper was first presented at the Ninth International Congress of Austronesian Linguistics (9ICAL), held at ANU, Canberra, in January 2002. I am grateful to Ross Clark, Bill Foley, John Lynch, Andrew Pawley and Gunter Senft, for the encouraging and inspiring remarks they made on that occasion; my thanks are also due to Catriona Hyslop, Boyd Michailovsky, Malcolm Ross and two anonymous readers, for commenting on earlier drafts of this paper. My research was funded partly by a scholarship of the Académie Française, and partly by the Centre National de la Recherche Scientifique (Langues et Civilisations à Tradition Orale).

${ }^{2}$ Mwotlap is an Oceanic language (North-Central Vanuatu subgroup) spoken by about 1800 speakers, mainly on the small island of the same name (François 2001; 2003). The language is also known as Motlav (e.g. Codrington 1885, Tryon 1976), and the island as Mota Lava.

${ }^{3}$ The spelling conventions adopted for Mwotlap include the following: $\bar{e}=[\mathrm{I}] ; \bar{o}=[\mathrm{U}] ; g=[\gamma] ; b=$ $\left[{ }^{\mathrm{m}} \mathrm{b}\right] ; d=\left[{ }^{\mathrm{n}} \mathrm{d}\right] ; q=\left[\mathrm{kp}^{\mathrm{w}}\right] ; \bar{m}=\left[\mathrm{ym}^{\mathrm{w}}\right] ; \bar{n}=[\mathrm{y}]$. The abbreviations used in literal translations include: AO 'Aorist', ART 'article', ASSO 'associative', CPLT 'Complete aspect', DAT 'dative', DEF 'definite', DU 'dual', DUP 'reduplicated form', DX:1/2/3 'deictic of first/second/ third grade', IMM 'Immediate future', LOC 'locative preposition', NEG 'negation', PCP 'locative participial', PFT 'Perfect', PROH 'Prohibitive', PRSP 'Prospective', REL 'relative marker', SUB 'subordinator', 1EX 'first exclusive', 1IN 'first inclusive'. In example sentences, directionals are enhanced using small capitals.

${ }^{4}$ In example (1), as is often the case, all spatial words concord semantically, since they all point to the same direction (descend, downwards, down, below...). Nevertheless, cases of discrepancy are also attested, which combine descend with up, and so on: see for example (31), (34), (36b/c).

5 These non-spatial meanings of directionals are limited, and specific to each form (François, in progress). For example, me 'hither' is sometimes used with a temporal meaning ( $\approx$ 'towards now'); van 'thither' may take an aspectual value (continuative, 'on and on'); hag 'up' and hōw 'down' are found in phrases connected respectively to the beginning and to the end of an activity [see (22), (37)-(38)]. But note that 'up' and 'down' do not show the kind of social, symbolic 
meanings—e.g. 'up' = honorific, 'down' = humility—which are attested elsewhere (OzanneRivierre 1997:90; Keesing 1997:134).

${ }^{6}$ Incidentally, the semantic constraints of van as a directional do not concern van as a verb ('go, whatever the direction' < POc *pano 'go away'). Along with the distributional criterion, this is a strong argument in favour of distinguishing them as two separate words in synchrony.

${ }^{7}$ The term "personal" should be taken in a broad sense: first, it is not related directly to the paradigms of personal forms (e.g. pronouns); second, the directional van can perfectly refer to an inanimate participant.

${ }^{8}$ Etymologically speaking, hag comes regularly from POc *sake '[go] upward'; hōw is an irregular reflex of POc *sipo '[go] downward', of which a more regular reflex is the verb heww 'descend'.

${ }^{9}$ As far as etymology is concerned, hay 'in' is cognate with Mota saro 'to draw into, to enter' (Codrington and Palmer 1896), in the same way as the verb hayveg 'enter' corresponds to Mota sarovag 'enter'. Yow 'out' is less certain; it recalls the verb yow 'fly away, jump' - cf. Mota rowo 'up; to spring, leap, move quickly forward' (<POc * Ropok 'fly').

${ }^{10}$ The situation in Mwotlap is thus very similar to that described for Balinese (Adelaar 1997:56), or for Kokota in the Solomon Is. (Palmer 2002:136). See François (f/c $b$ ) for further crosslinguistic comparisons.

${ }^{11}$ Similar remarks are proposed by Hill (1997:123). See also Bowden (1992:123) "Given the need for a reference point, the most natural one for a speaker to adopt is the speaker himself/herself".

${ }^{12}$ One will notice that this nuance is possible in Mwotlap, but irrelevant in many Oceanic languages which code 'inland' precisely in the same way as 'upwards' - e.g. New Caledonian languages (Ozanne-Rivierre 1997), or North-East Ambae (Hyslop 2001).

${ }^{13}$ It is difficult to propose a date for this innovation. But as far as we know, the metaphor "inland = in" is not attested anywhere else in Vanuatu than in Mwotlap, as well as neighboring Vurës and Mosina on Vanua-lava (pers. data). Outside Vanuatu, the same pattern is also witnessed in two North New Guinea languages around the Huon Peninsula, Yabêm (Streicher 1982: 151) and Mangap-Mbula (Bugenhagen 1995: 378). A deeper study of Oceanic languages should help improve our knowledge on such topics; see François ( $\mathrm{f} / \mathrm{c} b$ ).

${ }^{14}$ Such orographic explanations were proposed for other languages, whose system resembles superficially that of Mwotlap with $u p=$ east and down $=$ west. For example, in Tzotzil Maya, the east/west axis "roughly overlaps with the inclined topography of the region, for this reason E[ast] corresponds to the Highlands and W[est] to the Lowlands" (de León 1994, cited by Senft 1997:17; Palmer 2002:126). See also Ozanne-Rivierre (f/c) for a similar presentation of Iaai (Loyalty Is.), and François (f/c $b$ ) for the relevant discussion.

${ }^{15}$ This hierarchy is the reverse of the one assumed by Blust for western Malayo-Polynesian languages, when he says: "Within the monsoon region, the land-sea axis is restricted to cardinal north and south (since cardinal east-west is pre-empted by the monsoon terms), while outside the monsoon region this need not be the case" (Blust 1997:48; emphasis added).

${ }^{16}$ Hyslop (2001:217) reports that in the language of North-East Ambae, all foreign countries are designated as 'up', including the Solomons. This proves that the location of this country to the northwest of Vanuatu is not as salient for Ambae people as it is for the populations in the Banks.

${ }^{17}$ Most remarkably, the same phenomenon is reported for North-East Ambae (Hyslop 2001:216). The world is divided in two, the southeastern half being 'up' (hage) and the northwestern being 'down' (hivo); but because Malekula lies precisely across the way, it can be characterized neither as 'up' nor as 'down': instead, the language uses a neutral direction vano. Our map is inspired by hers. 